\title{
SPRAWLING AND URBAN TRANSPORTATION SYSTEM: IMPACTS IN THE CITY OF LONDRINA, PARANA, BRAZIL
}

\author{
M. POLIDORO ${ }^{1}$, J.A. de LOLLO ${ }^{2}$ \& M.V.F. BARROS 3 \\ ${ }^{1}$ Urban Engineering Department, Federal University of São Carlos, Brazil. \\ ${ }^{2}$ Civil Engineering Department, Sao Paulo State University, Brazil. \\ ${ }^{3}$ Geosciences Department, Londrina State University, Brazil.
}

\begin{abstract}
After nearly 80 years since the construction of its core, represented today by the city's central area, Londrina, located in the state of Parana, has the appearance of a new city but its features and trends of planning policies depict the bad examples of Brazilian cities. With a booming urban growth, from north to south of the county, the urban interstices represented by big voids in the middle of the city created speculation and the concept of an ideal city slowly disappeared. With a metropolitan appearance and, at the same time, with small town aspects, Londrina stands out as an automobile-oriented city, a fact that has impacted the livelihood of the population, generating environmental impacts for all social classes. This paper discusses how the form of occupation in Londrina, characterized by the sprawl phenomenon and its relation to car preference as a mode of transportation has generated urban environmental impacts. It was concluded that the choice of using cars in Londrina, as well in other medium-sized Brazilian cities studied by the comparative method, has increased and has generated bottlenecks in traffic. As a consequence, there is a constant expropriation of properties for widening roads and at the same time, the presence of various densities and urban voids that form an uneven urban space and an obstacle to efficient urban planning.
\end{abstract}

Keywords: automobiles, urban expansion, urban growth, urban sprawl, urban transport

\section{INTRODUCTION}

In this century's new decade, the urbanization phenomenon in Brazil has taken a new path with the partial consolidation of occupied areas to the detriment of rural areas. This new configuration, closely bound to new social relationships, has produced a mutation in the physical space, hence a new reality that emerges in the process, places that are neither rural nor urban [1].

The new reality, associated with public policies of massive infrastructure investments, such as highways and mega transit routes in certain regions, has built and promoted the emergence of new cities and the dispersal of others already established, where the political and administrative boundaries of municipalities are disappearing and giving way to a new landscape pattern that is characterized mainly by dense occupation in the surrounding outflow networks.

This, when observed at a regional scale, shows a contiguous occupation along highways connecting different cities and, when observed at an intra-urban scale, shows occupations removed from the consolidated center, with countless urban voids and an intense suburbanization process of various social magnitudes.

In the intra-urban space, incentives to purchase individual mode of transportation, through marketing or tax abatements, encourage the population to consider cars as the best choice to move around the city, while also appearing as a great option that allows choosing where to live, taking into account that such places may be distant from the locations that concentrate services and leisure.

This process leads to significant impacts in the intra-urban environment as well as in the regional plan. First, there is the increasingly spread out occupation of residences with automobiles as the primary mode of locomotion instead of collective public transport, deprived of any public investment. At the regional level, the concentration of occupations in bordering areas has established confining metropolitan areas, with the occupancy of residences, businesses, and industries, which create a complex logic in the urban sense as well as in its government. 
Thus, the influence regarding the choice of individual transport mode in the occupation of cities and the social and environmental impacts should be highlighted concerning the Brazilian reality, since there is an intense increase in the efforts to purchase vehicles. This article points the choice of automobiles as a mode of transportation in the city of Londrina as an essential factor in generating urban environment impacts.

In the first part, there is a discussion about the concepts and characteristics of urban sprawl, using mainly the North American and Brazilian literature. The impacts of the phenomena are discussed especially applied to medium-sized cities and metropolitan agglomerations where sprawl is more common.

Second part discusses how the private automobile influences the urban expansion guided by sprawl and how this transportation mode became important for the urban planning agenda. Furthermore, some characteristics caused by sprawl occupation and its relationship with car use in Londrina are pointed out.

Moreover, we separated the discussion of urban sprawl applied to the municipality of Londrina in two parts: first, we show the particularities of sprawl in the mentioned city and how it occurs, bringing some temporal data of the urban expansion. Next, some data and discussion regarding car use are presented, showing some comparative Brazilian cities that are the same size as Londrina. Finally, some considerations are made.

\section{URBAN SPRAWL: CONCEPTS AND CHARACTERISTICS}

The concept of urban sprawl has been divulged by researchers in the United States to characterize and explain the forms of occupation of many American cities to set up mitigating propositions for the numerous social and environmental impacts arising from the phenomenon, such as the smart growth policy applied in Portland, Oregon since the 1970s, a global benchmark in urban planning.

Burchell defines sprawl as: 'low-density, leapfrog development that is characterized by unlimited outward extension. In other words, sprawl is significant residential or nonresidential development in a relatively pristine setting. In nearly every instance, this development is low density, it has leapt over other developments to become established in an outlying area, and its very location indicates that it is unbounded' [2].

This is then characterized by the urban settlement spread that quickly reaches rural areas and is especially represented by these areas' low population density that extends beyond the consolidated center.

Johnson [3] adds that the sprawl phenomenon extends beyond service centers and job offers, therefore, separating the places where people shop, work, and even study from where they live. One of the main indicators of this phenomenon is the generation of large urban voids, in addition to a high decentralization of land belonging to the Government and its lack and/or inability to control the land value in tax collection, a fact that renders tax justice nonviable, thus aggravating social inequalities since tax collection is not proportional to the population's economic and spatial situation.

The consensus is that urban sprawling brings more harm than good to the urban space. Among the negative aspects, Burchell [4] emphasizes the following:

- Urban sprawl - Creating land subdivisions in places far from the consolidated center, hence creating numerous urban voids;

- Development of areas with low population density - Mainly in areas with individual houses (single homes) or higher income areas, leaving much of the installed infrastructure obsolete or underutilized; it can also be characterized by localities used only for commerce;

- Urban sprawl area - The disorderly physical-territorial delimitation of urban expansion areas decreases the agricultural areas and promotes land valuation in the rural-urban transforming process. 
The main urban sprawl features in Brazilian cities can be characterized by either the creation of new real estate by the local government or public and private land plotters to construct housing projects or high-income suburbs, as in the case of horizontal condominiums, all distant from the consolidated center.

This urbanization model far from the consolidated center, besides dividing the social classes, has generated some specific occupation characteristics. The housing projects or irregular occupation areas, like in several American cities, as shown by Carbonell [5], have been concentrated in the surroundings or in locations near the integration rings (this phenomenon is also seen in small Brazilian cities).

The environmental impacts resulting from this type of occupation occur for both the rich and the poor; however, the effects on lower income populations are more striking as they are far from the consolidated center, from commerce, from services, and from job opportunities. In addition to spatial segregation, it restricts infrastructure access such as public transport, which is essential for the population's daily work routine, often located in the central areas.

For the higher income population, although they have cars and transportation between cities is usually easier because the roads and avenues are better structured, there is traffic congestion in addition to high $\mathrm{CO}_{2}$ emissions, directly harming the environmental quality of cities and the population's health.

Another impacting factor in the regulation of land use and population density refers to strictly low-density commercial use, usually characterized by regions that concentrate "commerce corridors', usually in the vicinity of highways within the urban perimeter or in specialized service roads that also generate great impact, because to access such services, the population needs to move about by car or by public transportation, as indicated by Ojima [6]: 'The aspects that are considered as negative effects on urban sprawl models refers to the intensive use of automotive transportation, especially for individual use, and although this feature may be attributed as both cause and consequence, the truth is that the lower the population density, the higher the spatial displacement of the population for daily activities tends to be' [6].

Limonad, in an attempt to understand why the different social classes tend for suburban locations, shows a contrasting relationship [7] in the process: on the one hand, the social segment that holds the work force follows industrial relocation, usually along the urban periphery, and on the other hand, the wealthy populations that seek quieter places to live, away from the center.

This form of occupation by the different social classes along the urban fringe is characterized by low-density peripheral areas and is a worldwide phenomenon, with the exception of some clusters in the United States [7].

In this paper, we present urban sprawl in Londrina as a combination of: disperse land occupation due to new urban projects and real state; connections of these areas by roads and avenues that developed commercial corridors; lack of investments in public transportation to attend these new peri-urban areas; and the intense use of cars as the main transportation mode.

In Londrina, the urban sprawl is also characterized by the occupation of different social classes in the suburbs; however it is observed that the regions occupied by lower income inhabitants have population densities close to those found in the consolidated center, as is the case in the northern region of the city.

Common to all these situations, in the interstices of this occupation mode, the urban voids that are characterized by non-parceled areas occur frequently and are mainly in the hands of real estate agents, and although these are located in areas with complete infrastructure, they are used for speculation and land valuation. 
When these regions are located within the urban area limits, the owners of these lands wait for their valuation for speculative purposes, generating a type of non-contiguous development [8], given that oftentimes certain areas are intended for private condominiums, isolated from the consolidated areas, creating uninhabited land around them.

Those areas with low-density population, which are characterized mainly by buildings and homes and condos for singles, couples, or small families (for instance, couples with only one or two children) are usually distant from where commerce is concentrated - such as for instance shopping centers [8] and represent the social class that most use such services.

Besides the low-density areas, the expansion in the urban expansion limits, there is also the effect of sprawling, characterizing a peri-urban phenomenon with regard to urban expansion toward its periphery [9], that is, land use expands to the urban fringes, thus reducing agricultural areas and often damaging environmental preservation areas, where it is virtually impossible to identify whether the region is urban or rural. These areas: 'that earlier were traditionally linked to agricultural activities are now being used for industrial activities (mainly by the agro-industry), or by low-density residential occupations. Thus, the boundaries that once divided the urban and rural areas, with relative certainty, are increasingly less visible. Therefore, the debate regarding the criteria that define urban and rural areas is heightened to the extent that such boundaries are diluted by new forms of use and occupancy in peri-urban areas' [9].

In metropolitan areas, the headway of residence occupation in areas adjacent to other municipalities, for example, can cause substantial impacts if the instruments for urban planning, such as zoning, are not used.

These bordering areas usually concentrate both on industries as well as residential occupations, usually low-income, which often do not respect the urban policy instruments in the neighboring municipality, prompting major environmental impacts, primarily concerning neighborhoods [9].

While these regions concentrate on residential, industrial, and also commercial uses in locations that neighbor other municipalities, urban fragmentation in the territory causes: 'islands of various sizes and locations, defining full occupancy and voids. However, the steady advance of urban sprawl to the edges of the city shows that the dispersion appears to have no barriers, whether physical or social. In this case, the forces are predominantly of distension, with low density, pointing out the conflicts between accessibility and the use and occupation of urban land' [10].

All these aspects, correlated with forms of urban sprawl associated to cars, mainly caused by the disintegration of urban policies, lead to a systemic set of problems for Brazilian medium-sized cities and metropolitan agglomerations. This aspect will be discussed below.

\section{CHOICE OF TRANSPORT MODE AND ITS INFLUENCE ON URBAN AREAS}

Jong and Rouwette [11] discuss the impacts caused from the choice of using automobiles as the leading cause of urban sprawl. The density, for example, ends up generating activities when dispersed in low and middle levels.

Moreover, land use, usually homogeneous and segregated, uses indexes and restricted zones that eventually concentrate in certain specific service areas that require using automobiles for mobility.

The scale is another impact factor resulting from the intensive use of automobiles, since the city is envisioned from inside the car. This factor is also associated to street and connectivity designs. The projects are generally steered to vehicles and many properties are expropriated to make way for the widening of roads. Thus, walking and bicycling as a mode of transportation are jeopardized, because vehicles receive preference.

Furthermore, the creation of roundabouts, preference roads, and dead-end streets hinder pedestrians and human-powered transport. This planning model also inhibits public transportation to access certain areas. 
Lastly, the increasing use of land for road construction, or even shopping malls and private communities, reduces the space intended for public leisure activities, considering that individualism is increasingly present in urban life.

All these levels of impacts are also linked to institutional structuring problems, considering that often the departments of city governments are not integrated and create segmented and disconnected policies.

In addition, the low-density projects produced for single families create a scattered urban landscape, the induction of urban occupation in a linear direction, especially in small towns produced by installing large developments along highways. Morris [12] lists out four characteristics that are responsible for the urban sprawl.

- Lack of standards of multiple-use development - Lack of schools, work places, coffee houses, restaurants, offices, public buildings, and residences within walking distance.

- Automobile dependency - Since the basic functions of life in the city are scattered, the automobile is the only feasible mode of transportation, considering the precariousness of public transportation. Furthermore, new suburbs and vertical gated communities are designed to accommodate ever increasing numbers of parking spaces. Walking is eliminated as a safe way of going anywhere, thus quantitatively and qualitatively reducing sidewalks and social interaction.

- Gridlocks - The hierarchical divisions of secondary roads, which are usually linked to an arterial road, saturate at certain peak times. The lack of alternative routes and faulty geometric design of streets impair the locomotion of pedestrians and automobiles.

- Inadequate public transportation - Mass transportation is inadequate, poorly planned (usually, or initially, not included in land use planning), with the exception of transportation (generally private, for intercity travel) along main roads (avenues and highways).

Thus, pedestrians are left out as the main stakeholders in the planning of cities, giving space for private automobiles.

\section{URBAN SPRAWL IN LONDRINA}

The genesis of Londrina's urban occupation was mainly due to its economic potential on account of its strategic location, with its intra-city space represented by the main center, resulting from the joint actions of the ACL commerce association (Commerce Association of Londrina, nowadays including 'Industry' and called ACIL).

Regarding the ideology of 'pioneers' that persisted in the regional ruling class (formed mainly by foreigners) in the 1930s, Ribeiro [13] argues that the common idea of that group was to pursue 'Londrina's development' with the main objective of enriching the city, despite conflicts with the state government.

In the pursuit of this 'development', the group intensified its work to transform Londrina into an industrial city, especially after the agricultural crisis caused by the frost in 1975. It was from that moment, with the opportunities provided by urban areas, that the rural masses migrated to the city, which then concentrated many segments of commerce, becoming the urban area of Londrina.

From the 1950s, the occupation in the vicinity of the center expanded to areas where more popular districts were concentrating. Around the 1960s, there was an intense occupation growth in scattered regions that showed the phenomenon of sprawling, although some interstices were urbanized only later, however, with large urban voids.

Unaccompanied by urban transportation, the occupations became more sparse in the 1960s (Fig. 1), but it was followed by the sprawling phenomenon in the city. The phenomenon was also 


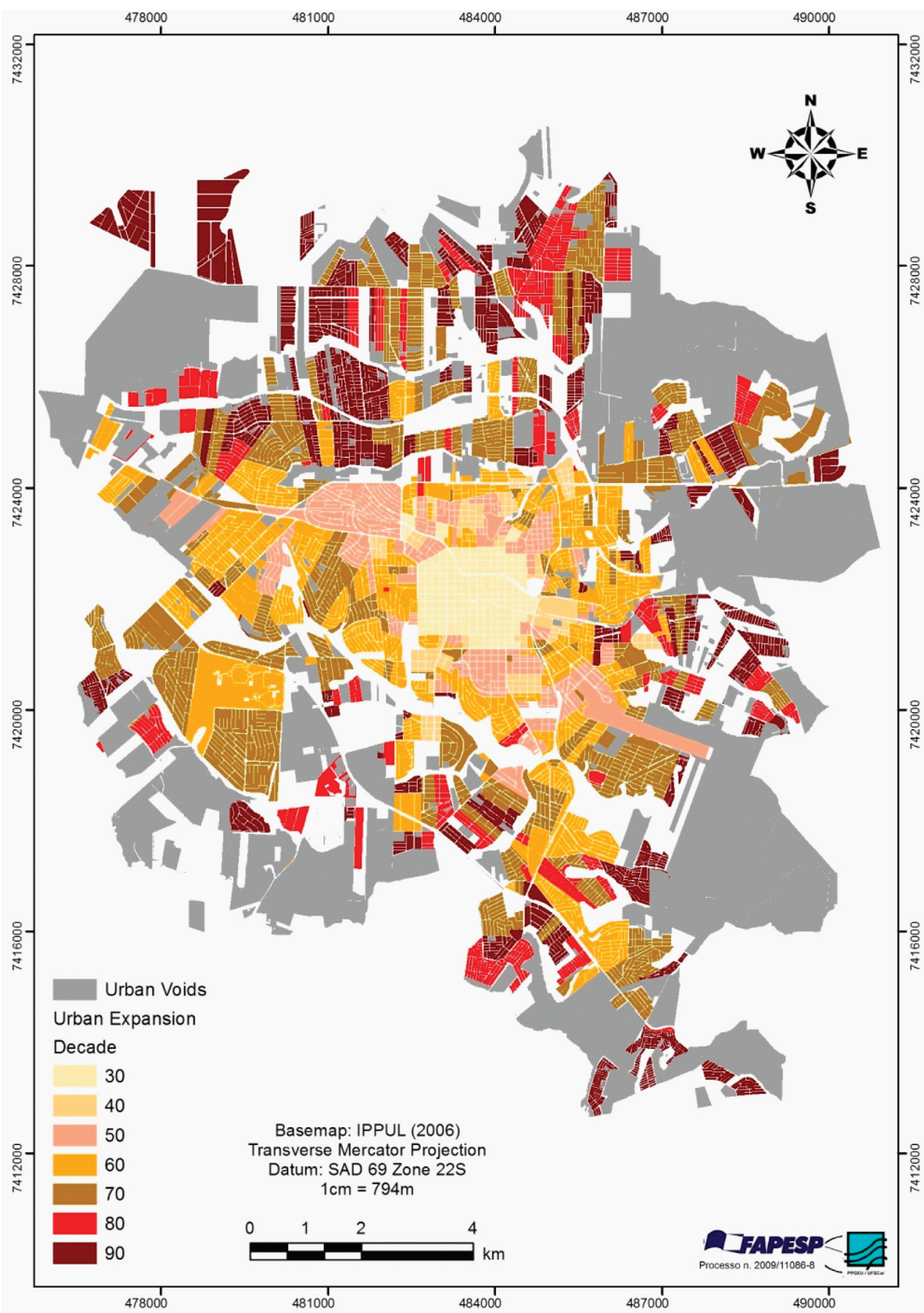

Figure 1: Urban expansion in Londrina - PR. Source: Polidoro [14]. 
seen, in this period, in many major US cities, as pointed out by [5], and in several Brazilian cities, particularly due to the political and economic model prevailing at that time, namely under Brazil's President Juscelino Kubitschek with the 'Target Plan'.

Razente [15] states that the emphasized urban sprawl in the 1960s stems from the deployment of the Igapó Lake, the airport construction, and the BR-369 highway, contributing to the dispersed occupation due to real estate speculation that the lake provided, as well as the highway, due to the construction of companies and housing projects in such surroundings.

In that same decade and with the participation of consultants from São Paulo, Londrina built its Master Plan, a technocratic Urban Development with great emphasis on the road system and zoning, initiating a process that greatly stimulated sprawl occupation in the direction of center-neighborhood [16].

The commerce in the center-north axis prompted the Master Plan, which intensified the occupation process in the form of sprawling and further intensified in the southwestern region, especially after the Shopping Center Catuaí was inaugurated in the late 1980s, which also included private universities.

These events prompted the emergence of numerous land lots for private communities consequently creating urban voids in the center-south route with complete infrastructure that are, however, underutilized and often obsolete. The housing demand grew and the single-type houses were increasingly sought [16].

From the 1970s, there was an intense population growth following the national trend. With the intensification of the rural exodus process, the rural population decreased from $42.60 \%$ in 1960 to $11.52 \%$ in 1980 reaching levels of only $6 \%$ in 1991; see Table 1.

After 1980, verticalization took new fronts and civil construction increased strongly, despite the economic crisis in the national context [17].

Table 1: Demographic data in Londrina - PR.

\begin{tabular}{|c|c|c|c|c|c|c|c|}
\hline \multirow[b]{3}{*}{ Year } & \multicolumn{6}{|c|}{ Resident population } & \multirow{3}{*}{$\begin{array}{c}\text { Geometric } \\
\text { growth } \\
\text { ratio(1) }\end{array}$} \\
\hline & \multicolumn{2}{|c|}{ Urban area } & \multicolumn{2}{|c|}{ Rural area } & \multicolumn{2}{|c|}{ Total } & \\
\hline & Population & $\begin{array}{l}\% \text { of urban } \\
\text { population }\end{array}$ & Population & $\begin{array}{l}\% \text { of rural } \\
\text { population }\end{array}$ & Population & $\%$ & \\
\hline 1950 & 34,230 & 47.93 & 37,182 & 52.07 & 71,412 & 100 & - \\
\hline 1960 & 77,382 & 57.40 & 57,439 & 42.60 & 134,821 & 100 & 6,60 \\
\hline 1970 & 163,528 & 71.69 & 64,573 & 28.31 & 228,101 & 100 & 5,40 \\
\hline 1980 & 266,940 & 88.48 & 34,771 & 11.52 & 301,711 & 100 & 2,82 \\
\hline 1991 & 366,676 & 94.00 & 23,424 & 6 & 390,100 & 100 & 2,36 \\
\hline 1996 & 396,121 & 96.19 & 15,000 & 3.81 & 411,000 & 100 & - \\
\hline 2000 & 433,369 & 96.94 & 13,696 & 3.06 & 447,065 & 100 & 2,02 \\
\hline
\end{tabular}

Source: IBGE - Brazilian Institute for Geography and Statistics - Demographic Census 1950, 1960, 1970, 1980, 1991, and 2000; Population count 1996.

(1) Tamarana population, which was a district of the Municipality of Londrina and already subtracted, was dismembered from it by State Law 11.224 of 13/12/1995.

Organization of data: PML/SEPLAN/Research and Information Management. 
From that moment on, an uneven urban setting began: the center consolidated the highest demographic density along with the housing projects in the north, to the detriment of many regions without any occupation or with low/average density, adjacent to the central area, equipped with infrastructure, forming urban voids in the interstices, Fig. 2.

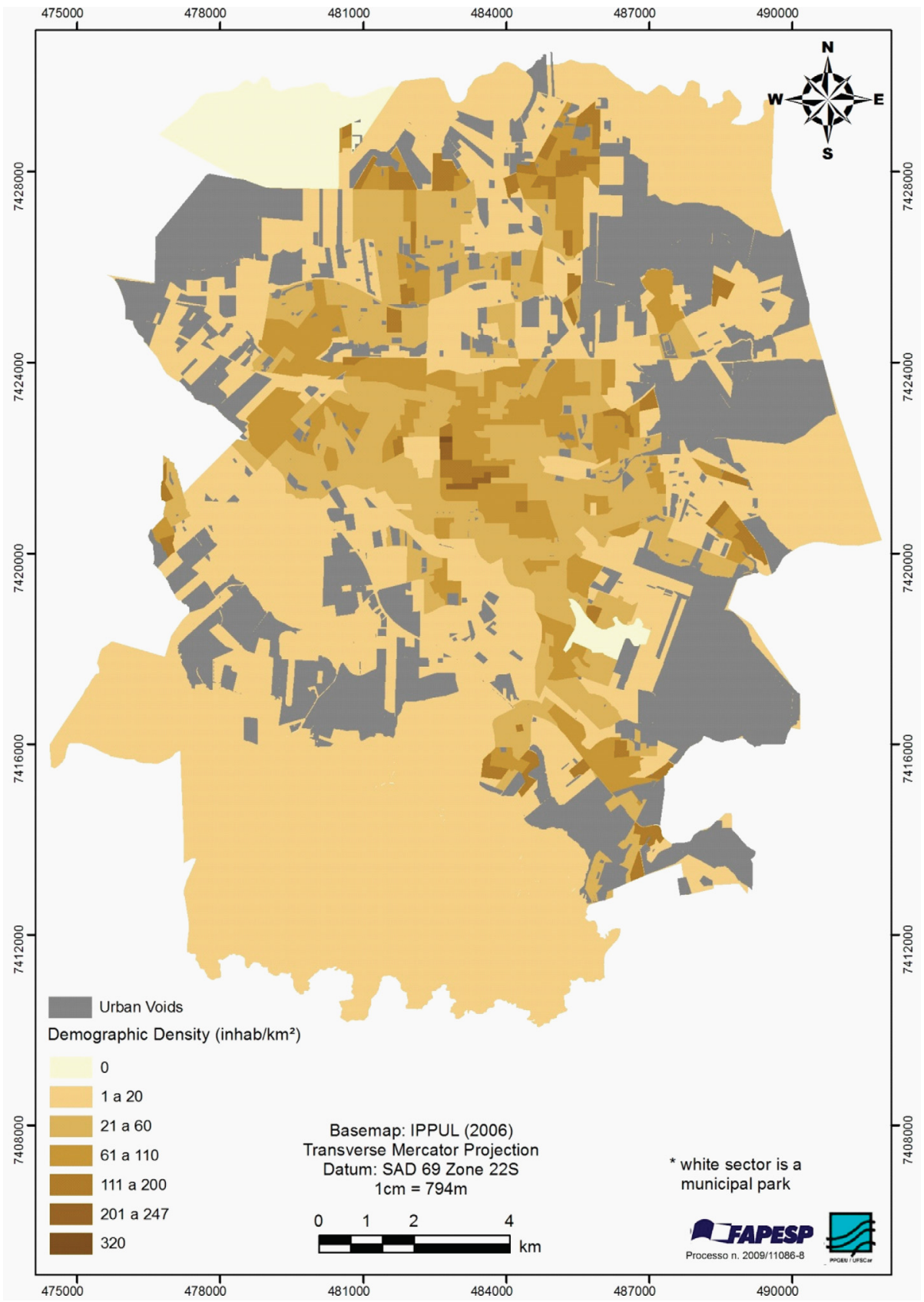

Figure 2: Demographic density and urban voids in Londrina - PR. 
The irregular occupations that were located on the outskirts of the city, such as in the south (steep slope) and permanent preservation areas in the east and north, began outlining a city of uneven density. Thus, the infrastructure installed in the districts adjacent to the central area began to supply low-demand regions, on account of the low number of inhabitants or even none at all, due to the large urban voids. Those located in peripheral areas of high population density were left with incomplete or nonexistent infrastructure.

\section{IMPACTS OF AUTOMOBILE USE IN LONDRINA, PARANA, BRAZIL}

The troublesome issue of air, water, and land pollution has been the source of numerous discussion forums in the technical and scientific realms as well as in the media. However, the issue of deforestation and global warming has been a more recurrent topic than the pollution generated in metropolitan areas.

Despite the 'second plan' in discussions on lifestyles in large urban areas, [9] points out that: 'transportation sectors will be one of the major components in the increase of direct GHG emissions, this processes will take place more palpably in urban areas. According to estimates compiled by researchers from COPPE/UFRJ (Post-Graduation Institute of Rio de Janeiro Federal University), energy consumption, which includes the consumption of fossil fuels, contributes about $75 \%$ of the emissions in São Paulo, followed by 23\% from the final disposal of solid waste' [9].

In other words, the discussions on deforestation and the waste generated in many cities are crucially important to environmental planning for the new century; however, some priorities must be raised in the discussion, such as the solution of traffic bottlenecks, the feasibility of investing in bike lanes, and the restrictions to construct a new way of life in urban areas.

It is observed that in Londrina the issue of automobile use is one of the biggest consequential factors of the sprawling phenomenon, bringing environmental pollution and spatial segregation problems. Regarding the impacts of greenhouse gases in Londrina, [18] show that: 'Given that every liter of fuel releases 2,3 $\mathrm{kg}$ of $\mathrm{CO}_{2}$, and that the total fleet of vehicles in Londrina in 2004 was of 183,952, then 347,779.651 tons of $\mathrm{CO}_{2}$ were emitted during this period. As 1.8 tons of $\mathrm{CO}_{2}$ emitted will be absorbed by each hectare of green area, and Londrina has 3,323 hectares of green areas, there is 5981,4 t for $\mathrm{CO}_{2}$ absorption in Londrina. Subtracting the values of tons emitted and tons absorbed, it comes to a total of 341.798,251t of $\mathrm{CO}_{2}{ }^{\prime}[19]$.

Using the ecological footprint as an urban sustainability indicator, the authors also claim that: 'The consumption of fossil fuels influenced the increase of the footprint due to the large number of individual vehicles, which demonstrates the need for governments to invest in quality public transport. One option is a bike path, which can be suitable in low slope areas' [19].

Despite the intent of some socio-educational programs in the area of transit and the environment (such as Transit Week, held annually and promoted by IPPUL Londrina Institute for Urban Planning and the conferences with environmental themes promoted by SEMA - Department for the Environment), the data from the Master Plan (Table 2) indicate a sharp increase in the choice of using cars as a transportation mode in the city. The Automobiles and Motorcycles categories in 2005 totaled more than $84 \%$ of the total vehicles in Londrina. And buses, the main transportation mode, appear in insignificant numbers when compared to the urban population of 510,707 inhabitants (IBGE, 2009).

The decreasing investments in public transportation, especially in areas where the poorer population lives (mainly in the peripheries), as seen in Fig. 3, characterize and intensify and uneven the urban space and the possibilities for that population to move around in the city, such as going to shopping centers and public parks (concentrated in the south region, close to the universities). The public transportation availability is mainly downtown and in neighboring regions. To the far south and north, where there is a greater concentration of low-income families, the frequency of public transportation is irregular or semi-regular (long waiting time for the buses). 


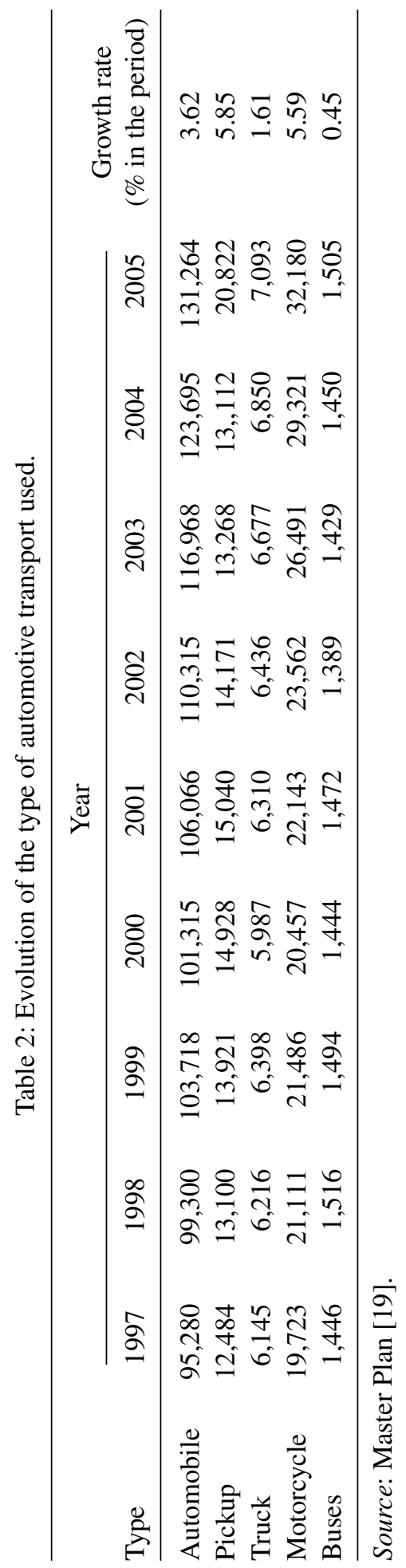




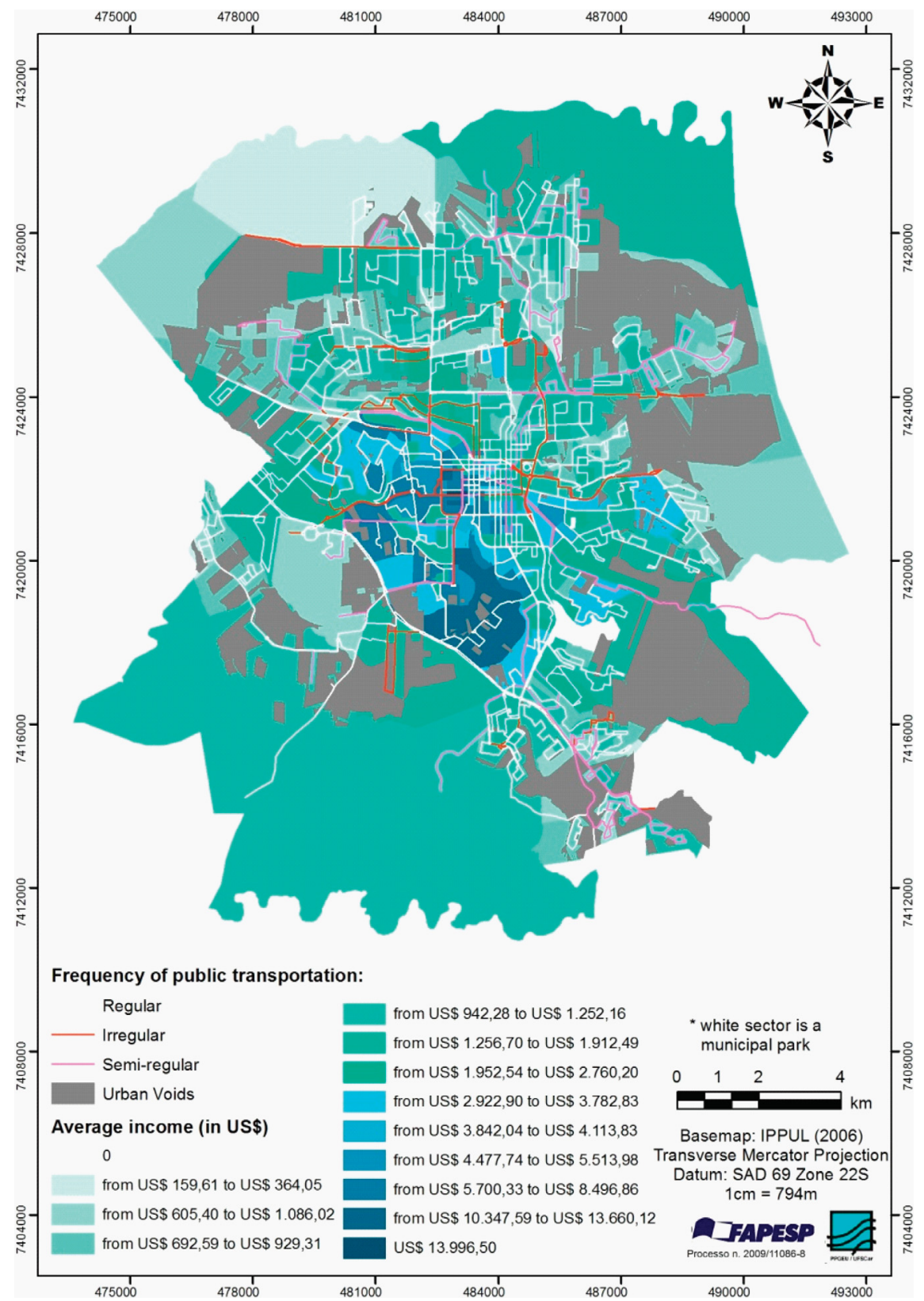

Figure 3: Average income and frequency of public transportation in Londrina.

Figure 4 clearly shows that most of the regions located in urban expansion areas and installed after the 1990s concentrate on the major percentage of urban voids and also the low-income population, outlining a scenario of intense social segregation. The higher-income population and private car users live near areas that have regular public transportation frequency, despite the fact they do not use such modes of transportation to commute. 


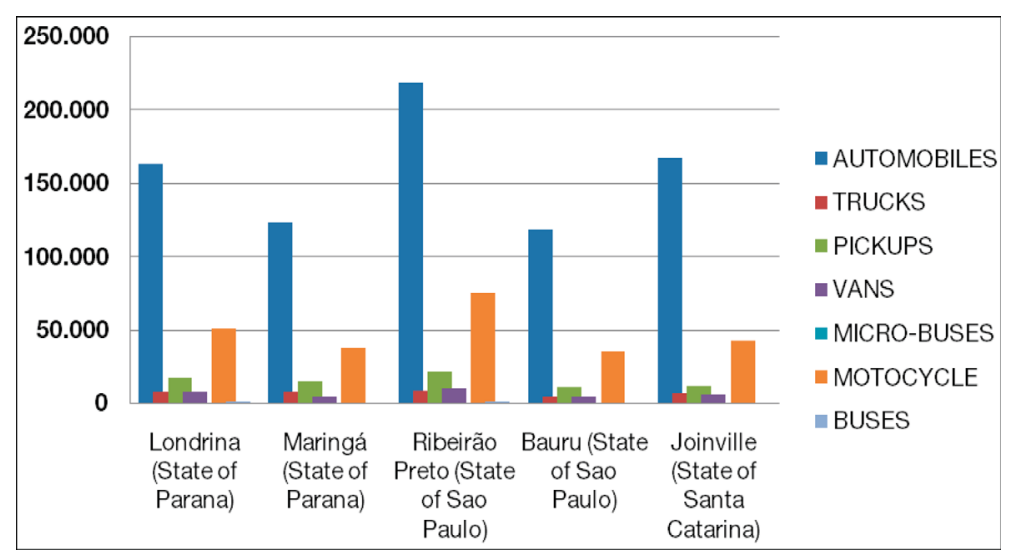

Figure 4: Types of transport most used in Brazilian medium-sized cities. Organization: Authors.

Table 3: Data on vehicles (motorized and bicycles).

\begin{tabular}{lccc}
\hline City & Total of population* & Total of automobiles & Motorizated rate \\
\hline Londrina (PR) & 510,707 & 163,904 & 32 \\
Maringá (PR) & 335,511 & 123,411 & 37 \\
Ribeirão Preto (SP) & 563,107 & 218,675 & 39 \\
Bauru (SP) & 359,429 & 119,159 & 33 \\
Joinville (SC) & 497,331 & 167,568 & 34 \\
\hline
\end{tabular}

Source: *IBGE estimate for 2009.

This situation is also found in other medium-sized Brazilian cities (from 60,000 to 1 million inhabitants) such as Londrina. Figure 4 illustrates the most used transport in some medium-sized cities, for a comparative analysis. The use of automobiles and motorcycles are much higher than other types of vehicles, especially regarding public transport (buses, minibuses) which is almost negligible.

The reasons for using the transport modes in Londrina, according to the data shown by [19], are 'work' (68.90\%), followed by 'other' (17.50\%), and also 'school' (8\%).

According to information published in [20] citing IPPUL in 2006, it was estimated that only $7 \%$ of Londrina residents used bicycle as a transportation mode; in municipalities, such as Bauru (inner city of São Paulo state), the use of bicycle and walking account for $28.2 \%$, and in the Metropolitan Region of São Paulo it comes to 34.4\% [21].

Londrina, in the context of medium-sized Brazilian cities, shows that the motorization rate (indicator used by the Brazilian transit department - DENATRAN - calculated by the number of fleets and divided by the total number of inhabitants multiplied by 100) is somewhat lower than in cities, such as Maringá and Ribeirão Preto. The excessive number of cars and motorcycles, as well as the reduced number of bicycles and buses, brings severe consequences to the quality of urban transport.

In this scenario, traffic in general, which is increasingly affecting Londrina especially in rush hours, a priori from $6 \mathrm{pm}$ to $8 \mathrm{pm}$, which now is progressively longer according to testimonies conveyed in [20], affects the users of public transport, due to the reduced number of preferential roads. 
Automobiles and bicycles are affected due to the lack of bike lanes as are pedestrians, who are victims of several streets with roundabouts, designed for cars.

The roads with the highest traffic (Fig. 5) are those linking the outlying areas, for example, the Housing Projects in the north, and universities and the Shopping Mall in the southern region in the center-direction and vice versa. In the case of Housing Projects, the daily commuting to the central

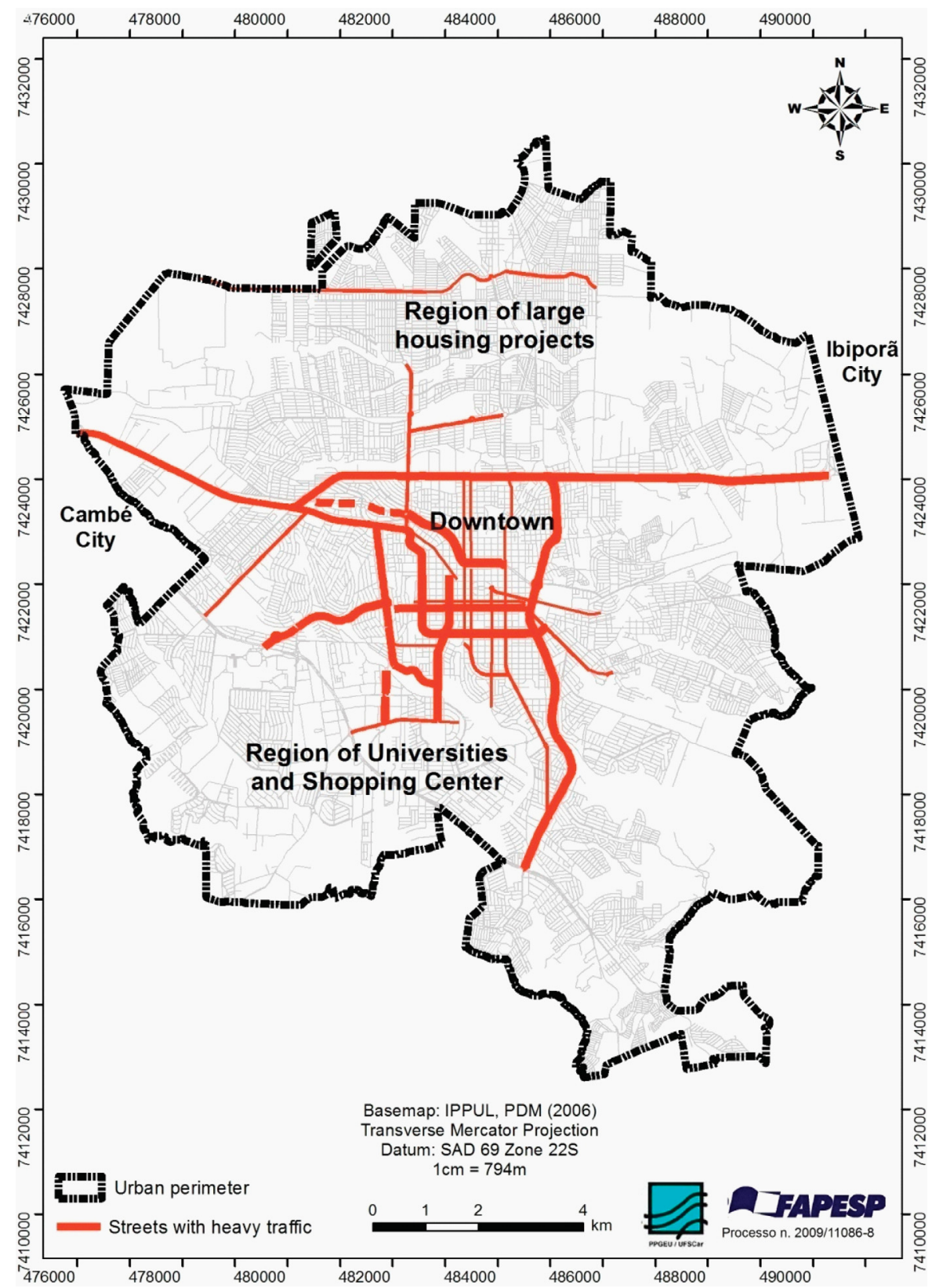

Figure 5: Road junctions in Londrina - PR. Source: PDM (2008). 
region and its surroundings, which is the place of work for a part of the population and the area having concentration of shops and services generates traffic bottlenecks caused by urban sprawling. The concentration in the Shopping Center and in the direction of universities (most valued area of the city) also causes road junctions and traffic bottlenecks are also found at certain points that connect the city to the cities and conurbations of Cambé and Ibiporã, given their high dependence on the polarizer.

Given this situation, there are increasing efforts by the planning agencies, such as IPPUL and the Municipality of Londrina, in partnership with the Inter-American Development Bank, for the construction of new roads, widening of others and expropriation, often located in the central region, in detriment to the implementation of bike lanes in places where residents could use them for everyday commuting or new bus lines or improving the existing ones, both in number and in quality, including adequate bus stops with covered waiting areas, often quite precarious.

\section{CONCLUSIONS}

The city has evolved into an increasingly complex formation due to its size and form as well as due to its social correlation. In this process, the mid-nineteenth century ideals of Urbanism of rationality for public investments and distribution of infrastructure and services necessary for urban life deviate increasingly more toward an uncertain future.

In this process, where the logic of urban space occupation is dictated by the intricacies of real estate speculators, in partnership with the Government, an unbridled expansion is seen impacting the city as a living space.

Social groups are increasingly seen heading out to the limits of the urban area, whether in search of job opportunities or cheaper housing. The more affluent also go in that direction, seeking a new lifestyle, far from the urban chaos, yet with different spatial practices and disproportionate access to resources.

This outlines a disproportionate city not only in terms of urbanization but also in terms of social relations, considering that the present moment signs a profound social crisis perceived by the deterioration of social relations, by the tendency of scarce neighborly relationships, by the shrinking of places to socialize (streets, small business district, town squares) by the implosion of neighborhoods, by deterioration of public spaces, and by the general lifelessness or emptying.

The departure from the consolidated area leads to new forms of social relationships, considering these relationships as the main stakeholders of urban space, customs that have impacted people's lives in their entirety.

The indiscriminate use of automobiles, for instance, has established itself as one of the requirements of this new lifestyle, since commuting long distances to obtain services such as schools, health services, leisure, and work require quicker and more comfortable mode of locomotion.

Coupled to policies and marketing that induce the use of cars, the population has chosen, when possible, to acquire these transport modes. Contrary to this event, there are the investments in public transport and roads accessible to pedestrians, who are renegades of cities that are increasingly becoming more specialized and centralized with activities.

This dialectic of urban expansion in Londrina has led the city to the exclusive use of cars. The concentration of services only in the central area and specific peripheral points, the uneven population density, coupled with the lack of appropriate planning strategies and the option of automobiles as the primary mode of commuting, creates traffic bottlenecks that paralyze the population's mobility, including those who use public transport.

As a result, in recent years, there have been efforts by Government to expand the roads through exorbitant high-priced enlargement projects involving property expropriations in the central region or the construction of bridges that leave pedestrian even more excluded from the urban space. 
This process, in constant movement in Londrina and in many other medium-sized Brazilian cities, must be managed, while there is still time. While the rapid urbanization goes beyond the political and administrative boundaries (as already in place in various metropolitan areas of Brazil and the world), new directions in urban planning and policies should be outlined, such as bike lanes and pedestrian paths. Another setback to be overcome is the institutional autonomy of the planning departments of the municipalities, which are at the mercy of legislature.

And in the case of planning in Brazil, it should be noted that the projects and plans to be outlined must overcome the political temporality and achieve the goals defined by popular sovereignty, and then, urban development can be sought - understood here as a principle that is expressed as social justice, quality of life and ecology - but which overall is inclusive.

\section{ACKNOWLEDGMENTS}

The authors are grateful to São Paulo's Research Support Foundation (FAPESP) trough the process n. 2009/11086-8, the National Council of Scientific and Technological Development (CNPq) and to the Federal University of São Carlos (UFSCar) for the Master's grant to the first author. CNPq is also acknowledged for support to project 06278. 'Digital Atlas of the Londrina Metropolitan Region, Brazil'.

\section{REFERENCES}

[1] Choay, F. O reino do urbano e a morte da cidade. In: Projeto História. São Paulo, n. 18, maio de 1999. p. 67-89.

[2] Burchell, R. \& Mukherji, S. Conventional development versus managed growth: the costs of sprawl. American Journal of Public Health. 93(9), 2003. doi: http://dx.doi.org/10.2105/ AJPH.93.9.1534

[3] Johnson, M.P. Environmental impacts of urban sprawl: a survey of the literature and proposed research agenda. Environment and Planning A. volume 33, pages 717-735, 2001. doi: http:// dx.doi.org/10.1068/a3327

[4] Burchell, R. The costs of Sprawl. Revisited. Transportation Cooperative Research Program Report. 39. Washington, DC: National Academy Press, 1998.

[5] Carbonell, A. \& Yaro, R. American spatial development and the new megalopolis. Land Lines. Lincoln Institute of Land Policy, 2005.

[6] Ojima, R. \& Hogan, D.J. População, urbanização e ambiente no cenário das mudancas ambientais globais: debates e desafios para a demografia brasileira. Anais do XVI Encontro Nacional de Estudos Populacionais. 13p, 2008.

[7] Limonad, E. Urbanização dispersa: mais uma forma de expressão urbana? Revista Formação (Presidente Prudente). N. 14, volume 1, 2007.

[8] Aurand, A.G. Is smart growth for low-income households: a study of the impact of four smart growth principles on the supply of affordable housing. Doctoral Thesis. 451p. University Of Pittsburgh, 2007.

[9] Ojima, R. \& Hogan, D.J. Crescimento urbano e Peri-urbanização: redistribuição espacial da população em novas fronteiras da mudança ambiental. Anais do IV Encontro da Associação Nacional de Pós-Graduação e Pesquisa em Ambiente e Sociedade. Brasília - DF, 2008.

[10] Ribeiro, E.L., Silveira, J.A.R. \& Viana, E.R.V. Controle do Sprawl Urbano, e Inclusão Social: o caso da cidade de João Pessoa - PB. Anais do IV Simpósio Internacional de Ciências Integradas. 12p, 2009.

[11] Jong, H de. \& Rouwette, A. Cycling-incluse policy development: a handbook. Disponivel em: <www.gtz.de/en/themen/28407.htm>. Acesso em: 21 de abril de, 2010. 
[12] Morris, D.E. It's a sprawl world after all: the human cost of unplanned growth - and visions of a better future. Gabriola, BC : New Society Publishers, 2005.

[13] Ribeiro, W.D. S. A Formação do Centro Principal de Londrina e o estudo da centralidade urbana. Geografia (Londrina), Londrina, v. 12, n. 2, p. 20-46, 2004.

[14] Polidoro, M. Sprawling urbano em Londrina: Desafio ao planejamento urbano. Monografia de Pós-Graduação em Análise e Educação Ambiental em Ciências da Terra. Universidade Estadual de Londrina. 76p. Londrina. 2010.

[15] Razente, N. Ocupação do espaco urbano de Londrina. Dissertação (Mestrado em Arquitetura e Urbanismo). Universidade Federal de Pernambuco, Pernambuco. 393f, 1983.

[16] Casaril, C.C. A expansão fisico-territorial da cidade de Londrina e seu processo de verticalização: 1950-2000. Revista Geografia (Londrina), v. 18, p. 65-94, 2009.

[17] Passos, V.R.L. A verticalização de Londrina: 1970/2000. Dissertação (Mestrado em Geografia, Meio Ambiente e Desenvolvimento). Universidade Estadual de Londrina. Londrina. 2007.

[18] Lisboa, C.K. \& Barros, M.V.F. A pegada ecológica como instrumento de avaliação ambiental para a cidade de Londrina. Confins [Online], 8 | 2010, posto online em 16 mars 2010, Consultado o 21 mai 2010. URL: http://confins.revues.org/index6395.html

[19] Master Plan Of Londrina. 2008. Disponivel em: <http://home.londrina.pr.gov.br/homenovo. php?opcao=home\&item=plano_diretor $>$. Acesso em: 10 de março de 2010.

[20] Jornal De Londrina. Gargalos do trânsito de Londrina. Reportagem: 13 de setembro de, 2009.

[21] Raia JR, A.A. Transporte para cidades sustentáveis. (Conferência). II Simpósio de Pós-Graduação em Engenharia Urbana. Maringá, 2009. 